\title{
To be accredited or not to be!
}

\section{Quality Assurance Unit, Faculty of Medicine, Ain-Shams University}

Quality assurance is defined as: "The means of ensuring that, informed by its mission, academic standards are defined and achieved in line with equivalent standards nationally and internationally, and that the quality of learning opportunities, research and community involvement are appropriate and fulfill the expectations of the range of stakeholders."

Accreditation is defined as "The recognition accorded by the agency to an institution which can demonstrate that its program meets acceptable standards and that it has in-place effective systems to ensure the quality and continuing improvement of its academic activities, according to the criteria published by the agency."

Accreditation provides an incentive for schools to introduce reform aimed at improving their educational performance and ensuring that both the schools and their graduates are fit for the purpose of promoting and improving the health of their communities. Globalization, information technology development, knowledge expansion and rapid development of communication systems that allow people to explore what is happening in different parts of the world have forced educators to think about curriculum changes that are responsive to these developments.

In the near future, graduates from the region will face difficulties in being recognized in other countries, and it will be more difficult for them to pass assessment tests before being allowed to practice. Licensing tests in the United Kingdom and United States, for example, now include sections on OSCE (Objective Structured Clinical Examination), ethics, problem-solving and information technology. In addition, many health agencies around the world are engaged in efforts to prepare a global accreditation system based on global standards. Medical schools in the region will be left out of this global recognition system if they are not involved in other accreditation schemes.

Accreditation serves two purposes: 1- To determine if an institution or program is in substantial compliance with accreditation standards.

2- To promote institutional improvement and renewal.

The accreditation process passes by the following steps:

1- A self-analysis (the institutional self-study) by the school,

2- An on-site review by a team of surveyors, and

3- A review of the survey team's written report.

Essentially, accreditation asks the following questions:

1- What are the objectives of the medical education program?

2- Has the institution organized its programs and resources to accomplish these objectives?

3- What is the evidence that the school is accomplishing its objectives?

Standards are useful for educational institutions as a basis for internal evaluation towards continuous quality improvement. They are also a necessary tool for external evaluation, recognition and accreditation of schools. Evaluation based on generally accepted standards is an important incentive for improvement and for raising the quality of medical education. Therefore, short-term results of accreditation should not be the basis for decisions to close schools or deny recognition to graduates. As described in the regional accreditation guidelines, accreditation is usually granted for periods of up to six years. When schools are found to have serious deficiencies, they are granted conditional accreditation for limited periods contingent upon certain issues to be addressed and actions to be taken by the school. If a school continues to be unable to deliver courses at the accepted standard, its students must be directed to another school to complete an accredited medical course before they can be recognized. 
Who are the customers in medical education process?

It is helpful to look at customers from two perspectives:

1- Internal customers (suppliers): Human resources (number and qualifications of personnel), material resources (facilities, equipment, and money), and organizational structure (medical staff organization, methods of peer review, and methods of reimbursement).

2- External customers (output): While the obvious external customers of medical education process are medical students and patients, there are others as well such as Ministry of Health, government agencies who pay for students, and community needs.

Current situation in the Faculty of Medicine, Ain-Shams University:

To improve both the content and delivery of the medical education program it was fundamental to apply quality tools. This required using every technique and process possible to ensure that staff and students are on the same page. The change process began 3 years ago with a year of planning during which faculty members were encouraged to join one or more of three relevant major committees (at both faculty and department levels) quality assurance, education development and accreditation committees. The main objectives to apply quality tools were:

1- Gain acceptance for change by improving awareness and teaching medical faculty how to apply continuous quality improvement to medical education.

2- Plan new curricula with innovative technological support for learning. For some specialities namely; Pediatrics, Obstetrics/genecology and Community Medicine, unified curricula were developed by the Supreme Council of the Universities (SCU) and distributed to all Egyptian universities. The rest of departments on individual basis are improving their own curricula according to World Federation of Medical Education (WFME) standards as requested by the vice dean for student affairs.
3- Develop new types of clinical education with the support of SCU.

4- Design new ways of student assessments. The faculty is striving to apply OSCE but resistance of staff is a major obstacle still. Unified learning guides and check lists are available now (for foundational, pediatrics, obstetrics/gynecology, and community medicine skills) are step ahead towards standardized teaching and assessment. Through the dean or SCU, a working group of expertise has to develop unified learning guides and check lists of the remaining specialities and adopt those already present.

5- Design and implement new types of admission policies. It is mandate to reduce the number of students to be admitted. Identifying areas in which quality can be improved in an organization; specific problems in the educational process can be identified applying Deming PDCA (Plan, Do, Check, Act) cycle as follows:

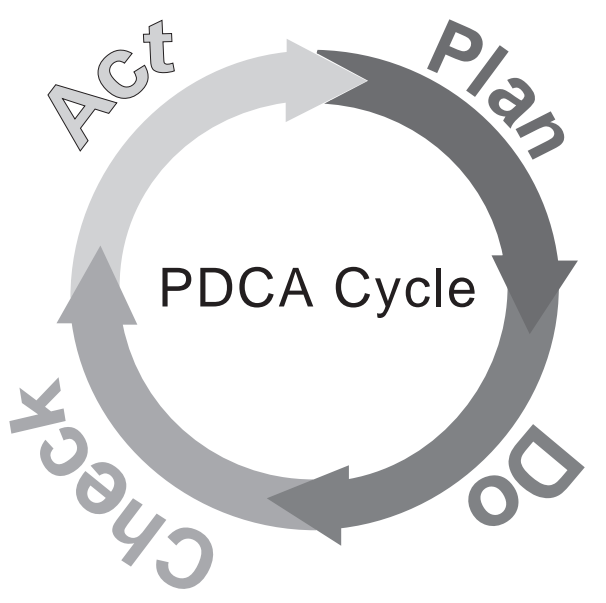

1- Plan; by preparing the environment and choosing a change or improvement.

2- Do; delegate a specific committee to address each area of the standards adopted (WFME). Establish thresholds for evaluation. Thresholds for evaluation are the levels or points at which intensive evaluation of care is initiated. Take action.

3- Check; Internal audit, non conformance to written standards will be identified and corrective actions agreed upon. A followup audit is to be planned to determine the degree of improvement.

4- Act; adopt the change and run through PDCA cycle again. 